Ingenium. Revista Electrónica de Pensamiento Moderno y Metodología en Historia de la Ideas ISSN-e 1989-3663

https://dx.doi.org/10.5209/inge.78433

\title{
Una ontología de la monstruosidad americana. Del monstruo fabuloso al monstruo ontológico
}

\author{
Bernat Castany Prado ${ }^{1}$; Christian Snoey Abadías ${ }^{2}$
}

Recibido: 29/04/2019 / Aceptado: 18/11/2020

Resumen. Este trabajo estudia de qué modo Europa concibió América, no sólo como un lugar habitado por monstruos, sino también como un espacio monstruoso en sí mismo, en tanto en cuanto su mera aparición supuso una alteración del orden ontológico anterior. A modo de ilustración se analizan de qué modo los europeos imaginaron y proyectaron sobre América cada una de las diferentes corrientes teratológicas (tardomedieval, renacentista y barroca) que predominaron durante los siglos XVI y XVII.

Palabras clave: ontología; otredad; monstruosidad; Historia de América; América colonial; crónicas de Indias.

\section{[en] An ontology of American monstrosity. From the fabulous monster to the ontological monster}

Abstract. This paper studies how Europe conceived America, not only as a place inhabited by monsters, but also as a monstrous space in itself, as soon as its mere appearance meant an alteration of the previous ontological order. By way of illustration we analyze how the Europeans imagined projected on America each of the different theratologic currents (Medieval, Renaissance and Baroque) that dominated during the $16 \mathrm{TH}$ and $17 \mathrm{TH}$ centuries.

Keywords: Ontology; Otherness; Monstrosity; History of America; Colonial America; Chronicles of the Indies.

Cómo citar: Castany Prado, B.; Snoey Abadías, C. (2020). Una ontología de la monstruosidad americana. Del monstruo fabuloso al monstruo ontológico, en Ingenium. Revista Electrónica de Pensamiento Moderno y Metodología en Historia de la Ideas 14, 25-34.

Muchos estudiosos consideran que el inicio de la Edad Moderna coincidió con un «boom teratológico» ${ }^{3}$. Ciertamente, aunque los monstruos también tuvieron una gran importancia en la época medieval, tanto en lo que respecta a las expresiones plásticas (capiteles románicos, miniaturas medievales), como en lo que respecta a las escriturales (textos bíblicos, exegéticos, enciclopédicos, hagiográficos, épicos, litúrgicos o legendarios) ${ }^{4}$, el interés por la monstruosidad parece haberse intensificado a lo largo de los siglos XVI y XVII.

Las crónicas de indias, los libros de viajes, los gabinetes de curiosidades, los tratados paradoxográficos, las profecías milenaristas, las disputas religiosas o las novelas estaban llenas de todo tipo de monstruos: demonios, leviatanes, caníbales, cinocéfalos, sirenas, hombres y mujeres salvajes o niños deformes. Añadamos, asimismo, los monstruos alegóricos de El criticón de Gracián, los Sueños de Quevedo, el monstruo de Rávena que aparece en el Guzmán de Alfarache (I, 1) de Mateo Alemán, $\mathrm{o}$, en un nivel más abstracto, la visión monstruosa del mundo que aparece en los Pensamientos de
Pascal. Según afirma Jean Delumeau, en su Historia del miedo Occidente (1978), esta efervescencia teratológica se debe, en buena medida, al «ascenso del miedo en Occidente en el alba de los tiempos modernos» ${ }^{5}$.

Resulta curioso considerar que esta profusión monstruosa coincidió con el resurgir del escepticismo humanístico, con la eclosión del racionalismo cartesiano y con el nacimiento de la ciencia, y, de forma general, con el inicio del proceso de desencantamiento del mundo, del que hablaría Max Weber en el siglo XIX, y que supondría que muchos monstruos empezasen a ser olvidados o refutados.

Podemos tratar de explicarnos dicha contradicción afirmando que la progresiva refutación de los monstruos, en particular, no supuso la desaparición de la monstruosidad, en general, sino, antes bien, su intensificación, ya que ésta dejó de ser vista como una excepción, exterior a la normalidad, para ser proyectada sobre toda la realidad, que pasó a ser vista como ese monstruoso espacio, infinito e indefinido, que exultó a Bruno, angustió a Pascal y embriagó a Nietzsche. Ese cambio supuso, evidentemente, el

\footnotetext{
Bernat Castany Prado es Profesor en el Departamento de Filología Hispánica, Teoría de la Literatura y Comunicación de la Universidad de Barcelona.

ORCID: orcid.org/0000-0001-7952-7646.

Email: bcastany@ub.edu

Christian Snoey Abadías es Investigador en la Universidad de Barcelona. ORCID: orcid.org/0000-0002-2563-4865.

Email: christian.snoey@uab.cat

Cf. E. Del Río Parra, Una era de monstruos: representaciones de lo deforme en el Siglo de Oro español, Madrid, Iberoamericana, 2003.

J. Leclerq-Marx, «Monstruos en la escritura, monstruos en imágenes, la doble tradición medieval», Quintana, 4 (2005), 13.

J. Delumeau, El miedo en Occidente, Madrid, Taurus, 2012, 21.
} 
paso de una monstruosidad fabulosa a una monstruosidad ontológica.

Cabe señalar, sin embargo, que, tal y como muestra Kappler, en su ya clásico estudio Monstruos, demonios y maravillas a fines de la Edad Media (1980), también en la época medieval el monstruo cumplía funciones metafóricas, rituales, iniciáticas e, incluso, estéticas, en las que no siempre se daba una creencia profunda en su existencia.

En todo caso, lo que aquí nos interesa no es hacer una historia de las fantasías y las supersticiones, sino reflexionar acerca del significado filosófico de la monstruosidad. Siguiendo la metodología propuesta por Borges en ensayos como «La muralla y los libros» o «La esfera de Pascal», incluidos en Otras inquisiciones (1952), donde llegará a considerar que «quizá la historia universal es la historia de la diversa entonación de algunas metáforas» ${ }^{6}$, trataremos de realizar una historia de las diversas entonaciones del monstruo en el paso de la Edad Media a la Edad Moderna, centrándonos sobre todo en el imaginario americano ${ }^{7}$.

Como era de esperar, el descubrimiento del continente americano supuso un renacimiento del género del bestiario medieval, en cuyas páginas la zoología y la teratología se entremezclaban sin una frontera precisa $^{8}$. La lista de monstruos es inacabable, y ha sido descrita y estudiada en muchas ocasiones ${ }^{9}$. Incluye monstruos de origen clásico (sirenas, cinocéfalos, centauros) $)^{10}$, medieval (gigantes, homo sylvestris) e indígenas (Tlaltecutli, la diosa de mil ojos, Cihuacoatl, la mujer culebra), si bien muchos de ellos pueden ser considerados, simplemente, universales. No es extraño que el monstruo tenga un papel tan importante en las Wunderkammers ${ }^{11}$. Tampoco que muchos hayan visto la mezcla como la esencia de la identidad o cultura americana (cuyo barroquismo llegaría hasta nuestros días con todo tipo de mezclas como las del populismo (que es un poder que finge representar a los que no lo tienen poder, en una especie de carnaval a la inversa), la tiranía (donde no existe la no separación de poderes y el tirano resulta monstruosamente deforme por falta de límites humanos), el sincretismo religioso, las extrañas alianzas entre comunistas, indigenistas y narcos, o grupos de nazis y judíos refugiados en los mismos países.

En un inicio, el monstruo americano heredó la ambigüedad moral, que lo hace oscilar entre la expresión divina y la creación demoníaca. San Agustín había tratado de mantener dicha ambigüedad en su célebre teoría del monstruo, incluida en La ciudad de Dios (XVI, 8), que pasaría a ser fundamental en la concepción del monstruo a lo largo de toda la Edad Media $^{12}$. Sin embargo, a partir del siglo XVI, ésta empezará a desaparecer en favor de la interpretación demoníaca del monstruo ${ }^{13}$. Con todo, en las crónicas de indias todavía domina la ambivalencia respecto del monstruo, que será visto ya como una expresión de la grandeza de Dios, ya como la prueba del poder del demonio en el Nuevo Mundo:

Los animales del Mundo Nuevo pueden ser criaturas maravillosas dotadas de cualidades y poderes curativos, un alimento exquisito y aptas para fabricar vestimentas y utensilios. Su presencia en esas tierras provoca la alabanza a la providencia divina, pero también pueden ser demonios o ídolos, monstruos o engendros diabólicos; en suma, el símbolo del mal y del señorío que el diablo tiene en las nuevas tierras ${ }^{14}$.

La conquista se ve, a la vez, como una exploración, que busca conocer y admirar los monstruos en tanto que expresión divina, y como una evangelización, que busca acabar con los monstruos del demonio. Sin embargo, dicha ambivalencia tenderá a verse simplificada por un proceso de especialización que transformará a los animales extraños como expresión de la grandeza divina y a los monstruos como creación diabólica.

A continuación analizaremos las cuatro formas fundamentales en que los monstruos americanos fueron concebidos, esto es, como expresión divina, como creación demoníaca, como soporte de un discurso moral, como mirabilia y, finalmente, como figura iniciática.

Veamos, en primer lugar, el monstruo americano en tanto que creación divina. Recordemos, para empezar, el tratado de Ambroise Paré, titulado Des monstres et prodiges (1573), que siguiendo en lo esencial la tradición teratológica medieval, considera que las dos primeras causas de la existencia de los monstruos son «la gloria de Dios» y «la ira de Dios». En el primer capítulo de Des monstres et prodiges, Paré distingue hasta catorce causas de los monstruos:

Las causas de los monstruos son varias. La primera es la gloria de Dios. La segunda su ira. La tercera, la cantidad excesiva de semen. La cuarta, la cantidad muy

\footnotetext{
J. L. Borges, «La esfera de Pascal», en Obras completas, Emecé, Buenos Aires, 1999, II, 16.

Según Kappler, podemos distinguir tres tipos de acercamientos fundamentales a la figura del monstruo: 1.- genético, que tiene en cuenta las causas (Aristóteles), 2.- teológico y estético, que tiene en cuenta la armonía del universo (San Agustín), 3.- ejemplarista o normativo, por su referencia a modelos de los que los monstruos son presentados como reproducciones imperfectas. Véase C. Kappler, Monstruos, demonios y maravillas a fines de la Edad Media, Madrid, Akal, 1986, 236.

E. López Parada, Bestiarios americanos. La tradición animalística en el cuento hispanoamericano contemporáneo, Madrid, Universidad Complutense, 1993, 27.

Véase al respecto M. J. Rodilla León, «Bestiarios del Nuevo Mundo: Maravillas de Dios o engendros del demonio», Rilce, 23-1(2007), 195-205.

Fray Marcos de Niza, por ejemplo, jurará haber visto rebaños de unicornios en Nuevo México.

J. Pimentel, Testigos del mundo: ciencia, literatura y viajes en la Ilustración, Madrid, Marcial Pons, 2003,152 y ss.

Kappler, Monstruos, demonios y maravillas a fines de la Edad Media, 331

ibid., 334.

Rodilla León, «Bestiarios del Nuevo Mundo: Maravillas de Dios o engendros del demonio», 203.
} 
escasa de semen. La quinta, la imaginación. La sexta, la angostura o estrechez de la matriz. La séptima, la posición indecente de la madre que cuando está embarazada se sienta por mucho tiempo con las piernas cruzadas o apretadas contra el vientre. La octava, por golpes dados en el vientre de la madre cuando está embarazada. La novena, por enfermedades hereditarias o accidentales. La décima, por podredumbre o corrupción del semen. La onceava, por mixtura o mezcla de semen. La doceava, por artificio de los perversos bigardos. La treceava, por los demonios o diablos ${ }^{15}$.

Para empezar, la idea de que el monstruo es el efecto de «la gloria de Dios», no deja de ser una teologización del viejo argumento de Aristóteles, que ya había afirmado, en La generación de los animales, que el monstruo es un fenómeno que va contra «la generalidad de los casos», pero no contra la naturaleza considerada en su conjunto ${ }^{16}$. Por si esto no fuese suficiente, la Biblia sugiere que Dios podría crear monstruos por su mera diversión o solaz, o por humillar y suspender la pretensión de los hombres de conocer su voluntad, tal y como parece afirmarse en el libro de Job (39-40) o en los Salmos (103, 25-26), donde llega a afirmarse: «tuyo es este mar tan grande y de tan anchurosos senos (...), ese dragón o monstruo que formarte para que retozara entre sus olas».

Después de Aristóteles y de la Biblia, la fuente más importante de dicha tradición se halla en La ciudad de Dios (XVI, 8), donde San Agustín se propone establecer una concepción de los monstruos que bloquee la posibilidad de que su existencia provoque en el creyente el más mínimo motivo de duda. Para el de Hipona, los monstruos no deben hacernos pensar que el Creador ha cometido un error: «¿Quién sería lo bastante loco para pensar que el Creador se ha equivocado, cuando ignora por qué razón ha hecho eso?»; por esta razón el hombre que duda no sabe «tener en cuenta el todo, se sorprende ante la aparente deformidad de una de las partes, pues desconoce la armonía y relaciones de ese todo» ${ }^{17}$. Estamos pues en el registro de la teodicea.

San Agustín no tiene problemas en aceptar que, con el monstruo, «la naturaleza se ha apartado de su curso habitual (abusitato cursu), como si se hubiera salido de su órbita (exorbitasse)», si bien este tipo de deformidad o anormalidad no implica fealdad, «puesto que contribuye a la hermosura del universo ${ }^{18}$.
En virtud de este enfoque holístico, el mundo medieval concibió los monstruos como seres que «pertenecían a un mundo maravilloso donde las cosas ocurren en una dimensión distinta a la humana» ${ }^{19}$, o, incluso, como "una "anomalía normal", un avatar necesario, inevitable, misterioso, pero no dramático, testimonio de la imaginación y de la creación divinas ${ }^{20}$. No es extraño que exista una conexión etimológica entre el sustantivo «monstruo- y el verbo «mostrar», ya que los monstruos son vistos como una expresión, o muestra, de la grandeza de Dios.

Por esta razón, dice Ambroise Paré, en el primer capítulo de su tratado teratológico, los monstruos no deben ser temidos ni rechazados, puesto que se nos revelan como la ocasión de conocer y de alabar a Dios: «En primer lugar, yo he recogido muchos monstruos (...) y he hecho grabar sus figuras y retratos a fin de que todos reconozcan la grandeza de la naturaleza, servidora del poderoso Dios.». Más aún, para Ambroise Paré, el monstruo es un juego de la naturaleza cuya función es que el hombre se admire del poder de Dios: "Nature s'y est jouée, pour faire admirer la grandeur de ses [de Dios] oeuvres $\rangle^{21}$.

Piénsese, por ejemplo, en el breve ensayo «De un niño monstruoso», de Montaigne, en el cual se afirma que:

Los que llamamos monstruos no lo son para Dios, que ve en la inmensidad de su obra la infinitud de las formas que en ella ha comprendido; y es de creer que esta criatura que nos asombra refleje y dependa de alguna otra figura del mismo género desconocida para el hombre. De su infinita sabiduría nada sale que no sea bueno y común y ordenado; más no vemos nosotros ni la armonía ni la relación ${ }^{22}$.

No es extraño, pues, que, tal y como estudia David Williams, en su libro El discurso deforme (1996), el monstruo se erigiese en una herramienta simbólica gracias a la cual se podía explorar «los secretos de la substancia, la existencia y la forma que se consideraban revelados de forma incompleta por el acercamiento más ortodoxamente racional de la dialéctica ${ }^{23}$. En la Edad Media, el lenguaje y la razón son considerados insuficientes para reflejar y explicar la divinidad y su creación, a las cuales no podemos acercarnos mediante un enfoque racional y descriptivo, sino sólo mediante paradojas, monstruosidades o ambigüedades, que nos ayudarían a trascender las

\footnotetext{
A. Paré, Monstruos y prodigios, Madrid, Siruela, 1993, cap. 1.

Aristóteles, La generación de los animales, Madrid, Gredos, 1994, IV, iv, 770b.

A. de Hipona, La ciudad de Dios, Madrid, Gredos, 2007-2012, XVI, 8.

Kappler, Monstruos, demonios y maravillas a fines de la Edad Media, 241.

R. Bartra, Wild men in the looking glass, Michigan, The University of Michigan Press, 1994, 100.

Kappler, Monstruos, demonios y maravillas a fines de la Edad Media, 132.

Paré, Monstruos y prodigios, 139, véase también 102, 117.

M. Montaigne, Ensayos, Madrid, Cátedra, 2006, II, XXX, 448.

D. Williams, Deformed Discourse: the Function of the Monster in Mediaeval Thought and Literature, Montréal, McGill-Queen's UP, 1996, 3. La traducción es nuestra: «the deformed functioned more often as a complementary, sometimes alternative, vehicle for philosophical and spiritual inquiry during this most intellectually speculative period of Western civilization... the Middle Ages made deformity into a symbolic tool with which it probed the secrets of substance, existence, and form incompletely revealed by the more orthodox rational approach through dialectics».
} 
limitaciones del lenguaje y el pensamiento racional ${ }^{24}$. Ciertamente, el estoicismo realizaba un uso no muy diferente de las paradojas. En Séneca, por ejemplo, las paradojas muestran aparentes contradicciones de la realidad, que son finalmente resueltas por la sabiduría, que conoce el logos. En el caso del cristianismo, el monstruo sería una especie de paradoja natural resuelta desde la perspectiva de la providencia divina. El monstruo sería, pues, según la distinción de George Steiner, una figura cómica, pues es más un malentendido que una contradicción, ya que su apariencia monstruosa es resuelta sin resto apelando a la instancia trascendente del plan divino o natural. En todo caso, en la Edad Media, el monstruo formaría una estrategia cognoscitiva, o más bien intuitiva, conectada con la teología negativa o apofática. Tanto es así que Dios llegará a ser considerado, por autores como San Agustín, San Isidoro, Escoto Erígena o el pseudo-Dionisio, como el creador de los monstruos ${ }^{25}$.

Como era de esperar, este mismo tipo de argumento será habitual en el corpus de las crónicas de indias. Pensemos, por ejemplo, en Gonzalo Fernández de Oviedo, quien afirmará, en el prólogo al libro XII de su Historia general y natural de las Indias (primera edición parcial de 1535, e íntegra entre 1851-1855), dedicado a la descripción de los animales americanos, muchos de los cuales serán presentados como «monstruos», que «el leer no ha de ser para el gusto de leer o entender cosas nuevas, sino para alabar y mejor conoscer al Criador e causa de todas ellas» ${ }^{26}$. También Ordóñez de Ceballos dirá, en su Viaje del mundo (1614), que no quiere contar esas verdades que parecen mentira sólo para entretener, sino sobre todo "para que se vean cuán grandes son las maravillas de Dios $»^{27}$.

Cabe señalar, asimismo, que Montaigne finaliza su célebre ensayo «Sobre los caníbales» afirmando que tendemos a considerar bárbaro aquello que no se amolda a nuestras costumbres: "Todo lo dicho en nada se asemeja a la insensatez ni a la barbarie. Lo que hay es que estas gentes no gastan calzones ni coletos» ${ }^{28}$; lo cual no deja de ser un final casi calcado al que cierra el ensayo, ya citado, «Sobre un niño monstruoso»: «Llamamos contra natura aquello que acontece contra la costumbre, más nada es sino según ella, sea como que sea» ${ }^{29}$. Nos encontramos, pues, con que la misma mezcla de terato-dicea agustiniana y de escepticismo humanístico que le servía a Montaigne para absolver a un «niño monstruoso», le sirve también para absolver a ese otro monstruo americano que era el caníbal.

Recordemos, sin embargo, con Ambroise Paré, que los monstruos no sólo pueden ser vistos como una muestra del poder creador de Dios ( «la gloria de Dios»), sino también de su poder castigador («la ira de Dios»). Quizás este aspecto no está tan presente en las crónicas de indias. De un lado, al ser representados los indios como seres inocentes que fueron engañados por el demonio, que, aprovechando la ausencia de Dios y de los cristianos, hizo en América lo que quiso, no van a merecer sufrir «la ira de Dios». Del otro lado, aunque los españoles sí van a merecer el castigo divino, por su codicia y crueldad, éste no va a ser infligido por monstruos (con algunas excepciones, como las de aquellos tigres de la Historia de los indios de la Nueva España, de Motolinía, que sólo atacarán a los españoles, mas no a los indígenas), sino, antes bien, por plagas, terremotos o tormentas ${ }^{30}$.

Veamos, a continuación, el segundo modo en que se conceptualizó al monstruo en América. Recordemos que el monstruo no sólo podía ser considerado expresión de la divinidad, sino también como creación demoníaca. Nuevamente, Ambroise Paré, en el primer capítulo de Des monstres et prodiges, afirma que la décimo tercera causa de la existencia de los monstruos son los demonios o diablos.

Para empezar, el mismo demonio se nos aparece como un monstruo en las Escrituras. En el Génesis, por ejemplo, el castigo que Dios le impone al demonio por haber tentado a Eva implica perder las alas y las patas («Sobre tu vientre caminarás y polvo comerás», Génesis 3,14), de donde surge probablemente la forma serpentiforme de los dragones. Por otra parte, en el Salmo 90, 13, que es la base del motivo del «Christus belliger», aparece el mal encarnado en la forma de un dragón, un león, un áspid y un basilisco; motivo que volverá a aparecer en el Apocalipsis. También en el Physiologus y en los muchos bestiarios medievales derivados de éste el monstruo aparece representado como una fuerza maligna ${ }^{31}$. Finalmente, en numerosas vidas de santos el demonio adopta la forma de monstruos (véanse las luchas de San Jorge y San Marcelo contra el dragón y de Santa Marta contra la tarasca), y en numerosas fórmulas de exorcismo aparecen referencias a serpientes, dra-

ibid., 4-6.

ibid., 9-17.

G. Fernández de Oviedo, Historia general y natural de las Indias, islas y tierra firme del mar Océano (1535), Asunción, Guarania, 1944, 61.

P. Ordóñez de Ceballos, Viaje del mundo (1614), Madrid, Miraguano-Polifemo, 1992, 453.

Montaigne, Ensayos, I, XXXI, 278.

ibid., II, XXX, 448.

Véase, por ejemplo, el primer capítulo de la Historia de los indios de la Nueva España, de Motolinía, donde se enuncian las diez plagas con las que «hirió Dios a dicha tierra»: la viruela; el sarampión; las muertes causadas por la guerra y por el hambre tras tenerse que abandonar los cultivos; los calpixques, o estancieros, y negros que maltrataban a los indígenas causándoles la muerte; los tributos excesivos; la minería y otros trabajos forzados de los indígenas; la reconstrucción de México que provocó un movimiento masivo de gente y, con ello, la extensión de enfermedades; la esclavitud; las enfermedades por la debilidad creciente de los indios, y, por último, la división y las luchas entre los españoles. Cf. F. T. B. Motolinía, Historia de los indios de la Nueva España, Madrid, Anejos de la Real Academia de la Lengua Española, 2014.

31 Leclercq-Marx, «Monstruos en la escritura, monstruos en imágenes, la doble tradición medieval», 13-53. 
gones y demonios meridianos ${ }^{32}$. Pero no sólo sucede que el demonio sea concebido como un monstruo, normalmente como un dragón, sino que el propio demonio quiera mostrarse tan grandioso como dios, $\mathrm{y}$ que en su prurito competidor e imitador de dios, haya creado monstruos.

Como era de esperar, en América se reproduce la ambivalencia teratológica que caracterizó al monstruo durante toda la Edad Media. Así, los monstruos americanos no sólo serán concebidos como una expresión divina, sino también como una creación demoníaca. En muchas crónicas religiosas la idolatría es considerada «algo así como un cáncer implantado por el Demonio», una especie de «extrañeza maligna de orden sobrenatural y ajena $»^{33}$. Este enfoque les servirá para resolver la paradoja de que los indios sean, a la vez, seres ingenuos y puros, y seres «salvajes», «caníbales», «sodomitas», «idólatras», «alcohólicos»y «sacrificadores de hombres». Diego Durán apuntaba, entre diversas explicaciones, que el demonio podría haber elaborado una religión falsa con el objetivo de hacerse venerar como si fuese el verdadero Dios. También Motolinía, en su Historia de los indios de la Nueva España, donde utilizará el término «demonio» unas 160 veces, presentará a los indios no como responsables de sus pecados, sino, más bien, como seres inocentes engañados por el demonio.

Habiendo sido América el territorio del demonio, no es extraño que aparezcan numerosos monstruos de origen demoníaco. En la Crónica del Perú (1553), de Cieza de León, el demonio se manifestará en forma de animal que copula con monas que acabarán engendrando:

...monstruos que tenían las cabezas y miembros deshonestos como hombres y las manos y pies como mona; son, según dicen, de pequeños cuerpos y de talle monstruoso, y vellosos. En fin, parescerán (si es verdad que los hay) al demonio, su padre ${ }^{34}$.

También Pedro Ordóñez de Ceballos afirmará, en su Viaje del mundo, haber visto un monstruo en las leoneras del emperador en Cochinchina:

...que era la cabeza y cara, hasta los pechos, de mujer, y lo demás de escorpión; tenía tres brazas de largo y llamábanlo marichas; dícese que la trajeron de las montañas de los Laos, de la provincia de Iangoma, y que hay muchas. Consideré que el demonio, cuando engañó a nuestra madre Eva, fue en esta forma, y tengo para mí que por allí cerca debe estar el paraíso terrenal $^{35}$.
Según Rodilla León, de la que he extraído los dos ejemplos anteriores, casi todos los monstruos demoníacos, que tienden a ser también encarnaciones de la lujuria, «son seres mixtos de parte humana femenina y parte animal como las esfinges griegas, las harpías, las furias clásicas, las gorgonas, las mujeres-serpientes -como Melusina-y las sirenas ${ }^{36}$.

No es extraño que la conquista y la colonización sea presentada como un gran exorcismo, que habrá de combatirse mediante el bautismo. Lo cierto es que, en aquel tiempo, todavía seguía vigente la concepción medieval de la conversión «ligada a una virtud mágica atribuida al bautismo», donde «el agua bautismal expulsaba el demonio del alma del judío, que repentinamente dejaba de causar miedo y se volvía inofensivo ${ }^{37}$. Este aspecto debe ser tenido en cuenta cuando consideramos, por ejemplo, el debate entre aquellos franciscanos de primera hora, que eran partidarios de los bautizos masivos, y aquellos que consideraban que éstos debían ser individuales y preparados por una catequización adecuada. Los primeros no eran ingenuos, ni cínicos; para ellos, el bautismo no era «una mera farsa sacrílega, sino un exorcismo del que se esperaba una conversión súbita. Por eso el resultado importaba más que los medios utilizados $\gg{ }^{38}$.

Antes de pasar al análisis del siguiente modo de concepción del monstruo, recordemos que en la época moderna se va a producir un giro radical en lo que respecta a la ambigüedad divino-demoníaca del monstruo, propia de la época medieval. Lo cierto es que, a partir del siglo XIV, como resultado del proceso de disolución del cosmos, entendido como un todo coherente y armonioso, por efecto de las pestes, guerras, corrupción, cismas o milenarismos, si bien el monstruo sigue siendo una criatura de la naturaleza, tenderá a acercarse cada vez más a la esfera de lo demoníaco, lo cual provocará, a su vez, que la relación epistemológica con él varíe, y ya no se busque contemplarlo, en tanto que modo divino, sino, sobre todo, conocerlo, con el objetivo de controlarlo o combatirlo ${ }^{39}$.

Veamos a continuación cómo los monstruos también fueron concebidos, en la línea de muchos bestiarios medievales o libros de fábulas, como figuras mediante las cuales se podía vehicular algún tipo de enseñanza moral. Esta práctica tiene un doble origen bíblico y grecolatino. De un lado, en el libro de Job ya aparece el motivo de los animales como mensajeros o instructores del hombre: «Pregunta a las bestias, y te instruirán; a las aves del cielo, y te lo comunicarán; a los reptiles de la tierra, y te enseñarán, y te lo harán

\footnotetext{
R. Caillois, «Les démons du midi», Revue d'Histoire des religiones, 115 (1937), 60.

3 E. O’Gorman, La incógnita de la llamada Historia de los indios de la Nueva España, atribuida a fray Toribio Motolinía, México D.F., Fondo de Cultura Económica, 1982, 35.

P. Cieza De León, La crónica del Perú (1533), Madrid, Dastin, 2000, 331.

Ordóñez de Ceballos, Viaje del mundo, 448-459.

Rodilla León, «Bestiarios del Nuevo Mundo: Maravillas de Dios o engendros del demonio», 203.

Delumeau, El miedo en Occidente, 361.

ibid., 362.

Kappler, Monstruos, demonios y maravillas a fines de la Edad Media, 335
} 
saber los peces del mar» (Job, 12, 7-9). Siguiendo el tópico del liber mundi, que afirma, tal y como recuerda Borges en tantas ocasiones, que Dios escribió dos libros, la Biblia y la naturaleza, que se complementan y se iluminan mutuamente, y el deber del hombre es leerlos y hallar las correspondencias.

Del otro lado, nos encontramos con libros como la Historia de los animales de Aristóteles (s. IV a.C.) y las Historias curiosas y el Sobre la naturaleza de los animales de Claudio Eliano (s. II-III d.C.), tradición que culmina en el Fisiólogo, de autor desconocido, escrito en Alejandría (ca. s. II-IV d.C.) Esta última obra tuvo una enorme repercusión en la Edad Media, en numerosas traducciones, glosas y citas, llegando a ser utilizada como manual o diccionario para la predicación, que fueron añadiendo a la primera versión, más moral, una interpretación alegórica-religiosa ${ }^{40}$.

En lo que respecta a América, nos encontramos con obras como el Sumario de González Fernández de Oviedo, donde se proyectan interpretaciones morales sobre los diferentes animales descritos. De este modo, los peces voladores que son cazados al vuelo por las gaviotas, son comparados con los hombres, ya que éstos corren "este mismo peligro (...) en las cosas de esta vida mortal», razón por la cual deberían «quitar los pensamientos del mundo, en que tan aparejados están los peligros, y poner en la vida eterna, en que está la perpetua seguridad» ${ }^{41}$. Lo mismo sucede con los cojijos, una especie de garrapatas, que, según Fernández de Oviedo, habrían sido creados para molestar a los hombres, dándoles a entender «cuán pequeñas y viles cosas son bastantes para los ofender e inquietar, y que no se descuiden del oficio principal para que el hombre fue formado, que es conocer a su hacedor y procurar cómo se salven $\rangle^{42}$.

Pero el monstruo, o el animal, no sólo pueden ser vistos como expresión divina, engendro demoníaco o soporte de una enseñanza moral, sino también como un recurso estético que sirve para colmar el gusto por la maravilla ${ }^{43}$, tal y como confiesa John Mandeville, en el inicio de sus Viajes, donde afirma escribir «porque muchos toman placer y solaz en oír fablar las cosas extrañas ${ }^{44}$. Según Kappler, no hay que esperar al Renacimiento y, mucho menos, al Barroco, para encontrarnos con el gusto por lo extraño o lo monstruoso, pues, ya en la Baja Edad Media, «la búsqueda de las maravillas constituye uno de los más importan- tes atractivos de la exploración del mundo ${ }^{45}$, como probaría el «estilo de charlatán de feria» con el que empieza el Libro de las maravillas de Marco Polo:

Señores, Emperadores y Reyes, Marqueses, Duques, Condes, Caballeros, Burgueses, y todos vosotros, en fin, que anheláis conocer las diferentes razas de los hombres y la enorme variedad de las diversas regiones del mundo ${ }^{46}$.

Curiosamente, este recurso, en parte retórico, contribuirá a que la cultura medieval identifique lo lejano con lo fabuloso, hasta el punto de que, en un giro paradójico, Colón llegará a sentirse obligado a subrayar el carácter fabuloso de las nuevas tierras descubiertas, con la intención de probar la verdad de sus descubrimientos. Según Kappler, las mirabilia que describe Colón en sus textos, «no se trata ya de narraciones fabulosas, sino de una realidad en que se confirma lo fabuloso $\rangle^{47}$. Después de Colón, los cronistas se limitarán a describir lo que ellos presentan como la realidad, negándose a identificarla con lo fabuloso. Tal sería el caso de Ordóñez de Ceballos, autor del Viaje del mundo (1614), según el cual, aunque es opinión común que el viaje sea sinónimo de patraña («suelen decir que de longas vías se suelen decir grandes mentiras»), su obra dice la verdad.

Veamos, para acabar, cómo la apelación al monstruo también puede entenderse como resultado de una necesidad universal, de corte psicológico o existencial. Según Kappler, existe «un sentido eterno y universal del monstruo» sobre el cual cada época imprime otros sentidos más propios y relativos (teológicos, culturales, convencionales), que «pueden oscurecer al primero, mas no impedir que exista ${ }^{48}$. Así, si en los libros de viajes no se siente una preocupación por diferenciar lo real de lo irreal, porque dicha distinción no resulta importante o pertinente para ellos, es porque, para la mentalidad arcaica, «lo sagrado es lo real por excelencia», de modo que el hecho de vivir o leer maravillas "no es, en modo alguno, ilusorio», sino que «pertenece a la experiencia sagrada del conocimiento del mundo que el hombre medieval persigue sin descanso ${ }^{49}$. Bajo esta luz, la maravilla se nos revela como «la ocasión para apercibirse de una acción y de una presencia más manifiestas de lo sagrado». Algo no muy diferente de esas «experiencias

\footnotetext{
40 Véase al respecto las páginas 55 a 67 de tesis doctoral de Marcos González-Mut, titulada Borges, antólogo de lo fantástico de lo fantástico: hacia una poética de lo fantástico, defendida en la Universidad de Barcelona en 2015.

1 Fernández de Oviedo, Historia general y natural de las Indias, islas y tierra firme del mar Océano, 263.

42 ibid., 242.

43 «Bien como aviso o señal (monere), o simplemente como algo digno de verse (monstrare), lo monstruoso entra en estrecha relación con otras dos palabras fundamentales y de connotaciones muy positivas para la teoría artístico-literaria del Siglo de Oro: la maravilla (mirabilia) y la admiración (admiratio), ambas etimológicamente vinculadas al acto de «mirar». Como explica Claude Kappler, estas palabras se derivan del latín mirari, la cual, como monstrum y portentum, "exprime l'étonnement, la surprise, le goût du nouveau et de l'extraordinaire"». Cf. R. Miñana, «El verdadero protagonista del Quijote», Cervantes: Bulletin of the Cervantes Society of America, 25.2 (2005), 40-44)

44 J. Mandeville, Viajes, Madrid, Cátedra, 1991, cap. 1.

Kappler, Monstruos, demonios y maravillas a fines de la Edad Media, 55.

Marco Polo, Libro de las maravillas del mundo, Madrid, Cátedra, 2008, 91.

ibid., 63.

Kappler, Monstruos, demonios y maravillas a fines de la Edad Media, 328.

49 Marco Polo, Libro de las maravillas del mundo, 127.
} 
límite» gracias a las que, según Karl Jaspers, revelamos o, más bien, producimos nuestro verdadero ser. Tal y como afirmarán Mircea Eliade, en Iniciaciones, ritos y sociedades secretas, Carl Jung y Karl Kerényi en Introducción a la esencia de la mitología, o Joseph Campbell, en El héroe de las mil caras, aunque los ritos iniciáticos que implican el enfrentamiento contra un monstruo o animal ya habían desaparecido en la Edad Media, persisten avatares populares, de corte imaginario, en los que «la imaginación será "trabajada" por esos mitos $»{ }^{50}$.

Pero no se trata exclusivamente de una cuestión existencial, sino también política, lo cual resulta especialmente interesante a la hora de estudiar las crónicas de indias. Lo cierto es que el enfrentamiento y la derrota del dragón eran vistos en la Edad Media como partes de un ritual de iniciación, purificación o prueba, que debía pasar el hombre llamado a reinar, quien demostraría, de este modo, que está en condiciones de defender el orden divino y la justicia ${ }^{51}$.

No es extraño, pues, que los conquistadores se presenten como vencedores de fieras, salvajes y monstruos. Lo cierto es que dichas apelaciones fabulosas no pueden explicarse únicamente porque estuviesen marcados por su peculiar imaginario literario, tal y como estudió Irving Leonard, en Los libros del conquistador (1949), sino también por su voluntad de presentarse como políticos cualificados, dignos de recibir encomiendas o gobernaciones, tal y como les vemos exigir en tantas probanzas de méritos y en obras, como la Historia verdadera de la conquista de la Nueva España, de Bernal Díaz del Castillo.

Sin embargo, la abundancia de monstruos en las crónicas de Indias no se debe solamente a razones religiosas, existenciales o políticas, sino también sociales. Según Miñana, Bernal Díaz del Castillo participaría de las mismas características monstruosas que don Quijote, quien, en virtud de «su carácter multiforme, su nacimiento, su sed de fama», y «su insaciable sed de "mostrarse" $»$, puede ser considerado un monstruo, «y especialmente el mayor monstruo de todos: el artista mismo, el dios de la creación y la metamorfosis $\gg{ }^{52}$. Por otra parte, los soldados plebeyos, como aquellos cuyo valor exalta el mismo Bernal Díaz, en su crónica, pretenden conquistar el derecho al valor, un atributo que, según estudia Delumeau, en su Historia del miedo en Occidente, estaba reservado a los nobles, y fundaba su derecho a reinar sobre una masa representada como cobarde. Curiosamente, el imaginario caballeresco del que se hallaban imbuidos los conquistadores puede explicarse, a su vez, como una estrategia de la nobleza empobrecida y amenaza- da por el ascenso social de la burguesía, que elaboró una mística del valor, tal y como puede constatarse en el auge de la novela de caballerías, que tenía como objetivo reforzar una nobleza amenazada, presentándola como el único grupo social capaz de defender y gobernar al pueblo, frente a villanos y burgueses, representados como cobardes ${ }^{53}$.

Por todo ello, América no sólo fue vista como un lugar lleno de monstruos, sino también como un lugar monstruoso en sí mismo. Señalemos que utilizamos una definición amplia de monstruos, que entendemos no sólo como un ser mitológico, sino también como un ser o una realidad que causa esa mezcla de asco y de miedo que es el terror, en virtud de su carácter ambiguo o impuro, tal y como sugiere Noël Carrol en su libro Filosofía del terror ${ }^{54}$.

Sería, ciertamente, un error considerar que esta efervescencia teriológica es una especie de resto puramente imaginario y medieval, que acabará desapareciendo con el tiempo. Me atrevería a decir que los monstruos fabulosos de los que hablan Colón o Marcos de Niza son los hijos de un monstruo mucho más poderoso y terrible, como es el mismo continente americano, en tanto que monstruo ontológico, cuya «aparición» provocó o catalizó el proceso de disolución de los límites cosmológicos, geográficos, sociales, religiosos, filosóficos o culturales, que había de llevar a la destrucción del «mundo» concebido como un todo finito y ordenado según valores trascendentes $^{55}$. En América todo parece ambiguo y, por lo tanto, monstruoso.

Aunque parezca una paradoja, América se nos revela como un lugar monstruoso, precisamente porque en contacto con él van a desaparecer muchos monstruos, esto es, la secularización del mundo va a verse catalizada, y en el mismo movimiento en el que desaparecen los monstruos del imaginario, el propio mundo se torna monstruoso, en el sentido ontológico que estamos contemplando.

Ciertamente, no es extraño que Pascal presente el universo como un lugar monstruoso, ni que Nietzsche afirme que esa facticidad pura, sin filtros, cuya mirada sólo puede sostener el superhombre, sea denominada lo Ungeheur, que Raúl Gabás propone traducir como lo monstruoso, en tanto que «desborda la dimensión apolínea, es decir, la realidad acuñada a través de formas precisas», de modo que también podría traducirse con los términos «inmenso», «informe» o «estremecedor» ${ }^{56}$. Así, según nos informa Safranski, para Nietzsche, en el año 1888, durante su último otoño en Turín, «lo monstruoso para él era que

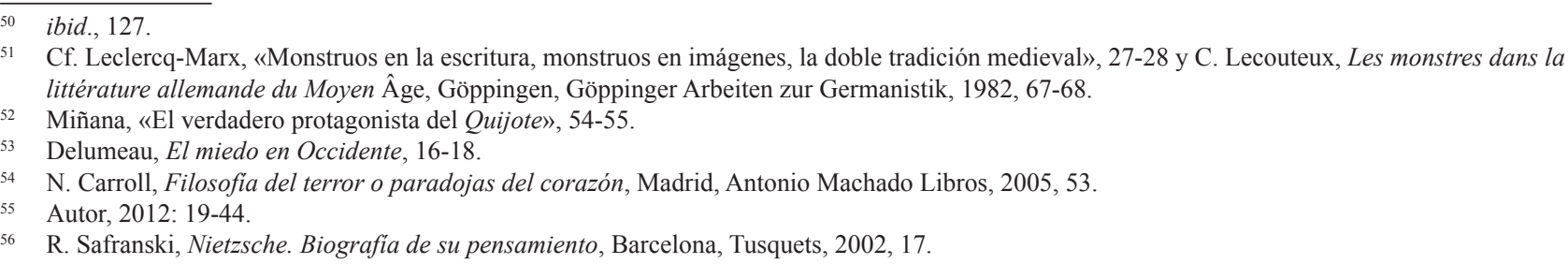


había sacado todas las consecuencias, incluso las más remotas, del descubrimiento de la muerte de Dios ${ }^{57}$.

Pero este proceso había comenzado mucho antes, tal y como muestra Paul Hazard en La crisis de la conciencia europea, y en él América no será un escenario menor. Lo cierto es que todas y cada una de las esperanzas, o miedos, de encontrar seres o lugares mitológicos, y en muchas ocasiones monstruosos, quedará inmediatamente frustrada, $\mathrm{y}$, aunque dichas expectativas serán relanzadas una y otra vez (el Dorado, el reino de las Amazonas o las Siete Ciudades de Cíbola fueron buscados prácticamente por todo el continente), la sombra del desencantamiento del mundo, catalizada por todos los procesos de secularización del pensamiento (humanismo) o de la sociedad (crisis de la sociedad estamental), se hará cada vez mayor.

Desde este punto de vista, América se nos revela como una «heterotopía», en el sentido de Foucault, quien no es casual que acuñase dicho término en diálogo con un texto de un latinoamericano, como Borges, titulado «El idioma analítico de John Wilkins», donde se juega, además, con una especie de Wünderkammer, que nos recuerda mucho a aquellas que nutrió América, como es el índice de una enciclopedia china inventada, supuestamente titulada Emporio celestial de conocimientos benévolos. La célebre enumeración caótica, que no deja de recordarnos a la misma realidad americana, constituye una reducción al absurdo del sueño de construir una characteristica universalis o lengua perfecta. América se nos revela, pues, como una heterotopía, esto es, como un espacio cultural o discursivo perturbador de los modos de conocimiento hegemónicos, puesto que destruye el sueño moderno de reconstruir el lenguaje, el conocimiento y el contexto político de la época, el entendimiento entre las religiones y las naciones. Así, frente a las utopías, que «consuelan», porque «se desarrollan en un espacio maravilloso y liso» y son «comarcas fáciles, aun si su acceso es quimérico», las heterotopías «inquietan, sin duda porque minan secretamente el lenguaje, porque impiden nombrar esto y aquello, porque rompen los nombres comunes o los enmarañan, porque arruinan de antemano la sintaxis $\gg\rangle^{58}$.

En resumen, América no fue sólo un lugar de monstruos, sino también un lugar monstruoso, un monstruo ontológico, en cuyo contacto todos los límites y distinciones entran en incandescencia hasta dar lugar a una todo descarnado y confuso. Al parecer, el monstruo no sólo defiende los límites, como sucede en los mitos y en los mapas, asustando o matando a los viajeros que osan acercarse a sus puertas (pensemos en la leyenda según la cual Alejandro Magno, tras llegar ante las murallas del paraíso, dispuesto a conquistarlo, vio desde lo alto a un ángel dejar caer una mota de polvo, y, comprendiendo, dio la vuelta y olvidó su empeño); sino también confundiendo sus pensamientos, como le sucedió a Penteo, quien, tras ser descubierto espiando los cultos de Dionisos, habría sido castigado a ver doble, imagen que, por cierto, utilizará la tradición escéptica, desde Erasmo hasta el Kant de las antinomias y los paralogismos de la razón.

En este sentido, el monstruo del viaje, y, en particular, del viaje a América, es el guardián de todos los límites, lo cual justificaría, por ejemplo, que, en la época medieval, existiesen «proscripciones contra las exploraciones geográficas $\rangle^{59}$, o que Pascal considerase que «toda la desgracia de los hombres procede de una sola cosa, que es no saber permanecer en reposo en una habitación ${ }^{60}$; lo cual no deja de estar en consonancia, por ejemplo, con el libro de Job, donde se le insta al hombre a no tratar de conocer los límites del mundo. Pero cuando se ve a los monstruos desde cerca, éstos dejan de ser la garantía del orden, para transformarse en el símbolo de la decadencia provocada por ese mismo encuentro.

\section{Bibliografía}

Agustín de Hipona (2007-2012): La ciudad de Dios, Madrid, Gredos.

Bartra, Roger (1994): Wild men in the looking glass, Michigan, The University of Michigan Press.

Borges, Jorge Luis (1999): «La esfera de Pascal», en Obras completas, Emecé, Buenos Aires, 4 vols.

Bouthoul, Gaston (1970): Traité de polémologie, París, Payot.

Caillois, Roger (1937): «Les démons du midi», Revue d'Histoire des religiones, 115, 58-66.

Campbell, Joseph (1980): El héroe de las mil caras, México D.F., Fondo de Cultura Económica.

Carroll, Noël (2005): Filosofia del terror o paradojas del corazón, Madrid, Antonio Machado Libros.

Castany Prado, Bernat (2014): «Las galas del mundo fuera de ley. Indios e indianos como cristianos nuevos y cristianos viejos en las Cortes de la muerte de Miguel de Carvajal», Anagnórisis. Revista de investigación teatral, 9, 6-39.

Castany Prado, Bernat (2015): «Ovidio transformado. La presencia de Ovidio en las dos primeras partes del Parnaso Antártico de Diego Mexía de Fernangil», en Clásicos para un Nuevo Mundo. Estudios sobre la tradición clásica en la América de los siglos XVI y XVII, Bellaterra, Centro para la Edición de los Clásicos Españoles, 53-85.

\section{ibid., 329.}

58 M. Foucault, Las palabras y las cosas. Una arqueología de las ciencias humanas, Madrid, Siglo XXI, 1997, 6. Véase al respecto las interesantes consideraciones de Esperanza López-Parada en su libro Bestiarios americanos, 128-130.

59 N. Thrower, Mapas y civilización. Historia de la cartografía en su contexto cultural y social, Barcelona, Ediciones del Serbal, $2002,52$.

60 B. Pascal, Pensamientos, Madrid, Valdemar, 2001, \$136. 
Castany Prado, Bernat (2012): «Perdida toda coherencia: El impacto de América en la "crisis de la conciencia europea"», Anales de Literatura Hispanoamericana, 41, 19-44.

Cieza de León, Pedro (2000): La crónica del Perú (1533), ed. de Manuel Ballesteros, Madrid, Dastin.

Delgado, Manuel (2007): «La violencia como certidumbre», reseña de El rechazo de las minorías. Ensayo sobre la geografía de la furia, de Arjun Appadurai, El País, 27 de octubre de 2007.

Del Río Parra, Elena (2003): Una era de monstruos: representaciones de lo deforme en el Siglo de Oro español, Madrid, Iberoamericana.

Delumeau, Jean (2012): El miedo en Occidente, Madrid, Taurus.

Durand Flórez, José (1983): Ocaso de sirenas, esplendor de manaties, México D.F., Fondo de Cultura Económica.

Eliade, Mircea (1992): Initiations, rites, sociétés secrètes, París, Gallimard.

Fernández de Oviedo, Gonzalo (1944): Historia general y natural de las Indias, islas y tierra firme del mar Océano (1535), Asunción, Guarania.

Foucault, Michel (1997); Las palabras y las cosas. Una arqueología de las ciencias humanas, Madrid, Siglo XXI.

Gerbi, Antonello (1960): La disputa del Nuevo Mundo, historia de una polémica 1750-1900, México D.F., Fondo de Cultura Económica.

Girardet, Raoul (1986): Mythes et mythologies politiques, París, Éditions du Seuil.

González-Mut, Marcos (2015): Borges, antólogo de lo fantástico de lo fantástico: hacia una poética de lo fantástico, tesis doctoral defendida en la Universidad de Barcelona.

Greenblatt, Stephen (1991): Marvelous Possessions. The wonder of the New World, Chicago, The University of Chicago Press.

Jáuregui, Carlos A. (2008): Canibalia. Canibalismo, calibanismo, antropofagia cultural y consumo en América Latina, Madrid, Iberoamericana Editorial Vervuert.

Jung, Carl Gustav - Kerényi, Karl (2012): Introducción a la esencia de la mitología, Madrid, Siruela.

Kappler, Claude (1986): Monstruos, demonios y maravillas a fines de la Edad Media, Madrid, Akal.

Leclercq-Marx, Jacqueline (2005): «Monstruos en la escritura, monstruos en imágenes, la doble tradición medieval», Quintana, 4, 13-53.

Lecouteux, Claude (1982): Les monstres dans la littérature allemande du Moyen Âge, Göppingen, Göppinger Arbeiten zur Germanistik.

León Pinelo, Antonio de (1994): Cuestión moral, sobre si el chocolate quebranta el ayuno eclesiástico, México D.F., Centro de Estudios de Historia de México.

Leonard, Irving A. (2009): Los libros del conquistador, México D.F., Fondo de Cultura Económica.

Lévi-Strauss, Claude (1980): «El análisis estructural en lingüística y en antropología», en Antropología estructural, Buenos Aires, Budeba, 29-51.

López Parada, Esperanza (1993): Bestiarios americanos. La tradición animalística en el cuento hispanoamericano contemporáneo, Madrid, Universidad Complutense.

Mandeville, Sir John (1991): Viajes, Madrid, Cátedra.

Miranda, José (ed.) (1950): Sumario de la natural historia de las Indias (1526), México D.F., Fondo de Cultura Económica.

Motolinía, Fray Toribio de Benavente (2014): Historia de los indios de la Nueva España, Madrid, Anejos de la Real Academia de la Lengua Española.

Montaigne, Michel de (2006): Ensayos, Madrid, Cátedra.

Miñana, Rogelio (2005): «El verdadero protagonista del Quijote», Cervantes: Bulletin of the Cervantes Society of America, 25-2, 31-58.

Norton, Marcy (2006): «Tasting Empire: Chocolate and the European Internalization of Mesoamerican Aesthetics», The American Historical Review, 111-3, 660-691.

O'gorman, Edmundo (1982): La incógnita de la llamada Historia de los indios de la Nueva España, atribuida a fray Toribio Motolinía, México D.F., Fondo de Cultura Económica.

Ordóñez de Ceballos, Pedro (1992): Viaje del mundo (1614), Madrid, Miraguano-Polifemo.

Pagden, Anthony (1988): La caída del hombre natural, Madrid, Alianza.

Paré, Ambroise (1993): Monstruos y prodigios, Madrid, Siruela.

Pascal, Blaise (2001): Pensamientos, Madrid, Valdemar.

Pimentel, Juan (2003): Testigos del mundo: ciencia, literatura y viajes en la Ilustración, Madrid, Marcial Pons.

Polo, Marco (2008): Libro de las maravillas del mundo, Madrid, Cátedra.

Rodilla León, María José (2007): «Bestiarios del Nuevo Mundo: Maravillas de Dios o engendros del demonio», Rilce, 23-1, 195-205.

Safranski, Rüdiger (2002): Nietzsche. Biografía de su pensamiento, Barcelona, Tusquets.

Thrower, Norman J. W. (2002): Mapas y civilización. Historia de la cartografía en su contexto cultural y social, Barcelona, Ediciones del Serbal.

Todorov, Tzvetan (2005): La conquista de América, México D.F., Siglo XXI.

Urdapilleta, Marco Antonio (2002): Bestiario de Indias (antología). Toluca, UAEM. 
Williams, David (1995): Deformed Discourse: the Function of the Monster in Mediaeval Thought and Literature, Montréal, McGill-Queen's UP. 